\title{
O Atlas Lingiístico de Mato Grosso do Sul
}

\author{
Dercir Pedro de OLIVEIRA \\ $\mathrm{CNPq} / \mathrm{UFMS}^{1}$
}

Resumo: O projeto Atlas Lingǘstico de Mato Grosso do Sul tem o propósito de oferecer aos estudiosos e professores subsídios para incorporar ao ensino da língua a diversidade lingüística, apontando as características lingüístico-culturais das diferentes regiões do Estado. A pesquisa faz uso de métodos da geolingüística e da sociolingüística de tal modo que os dados possam servir de base para estudo de aspectos histórico, geográfico, social, ecológico e etnográfico de Mato Grosso do Sul. As entrevistas são realizadas pelo método direto e indireto, gravadas e transcritas fonética e grafematicamente. Os informantes são estratificados em sexo, faixa etária, grau de instrução e naturalidade. São trinta e duas localidades, cada qual com quatro informantes (dois masculinos e dois femininos).

Palavras-chave: Atlas; variações; localidades

Abstract: The Atlas Lingüístico de Mato Grosso do Sul project has the purpose of offering support for researchers and teachers to incorporate the linguistic diversity into the language teaching, evidencing the linguistic cultural characteristics from different regions of the state of Mato Grosso do Sul. The research employs geolinguistic and as for sociolinguistic methods bases for the study of historical, geography, social, ecological ant ethnographic aspects of Mato Grosso do Sul. The interviews are done by direct and indirect method, and they are phonetically and graphematically transcribed. The informants are stratified in sex, age, level of instruction and place of birth. The search embraces thirty-two localities with four informants in each (two male and two female one).

Keywords: atlas; variations; localities

\footnotetext{
${ }^{1}$ Agradeço a Adriana Viana Postigo e a Juliana Cristina Fresqui a leitura dos originais. O conteúdo é de minha inteira responsabilidade.
} 


\section{Introdução}

O objetivo deste artigo é o de dar ao leitor conhecimento sobre o Projeto Atlas Lingǘstico de Mato Grosso do Sul e a fase de elaboração em que se encontra, destacando a importância da dialetologia na pesquisa da realidade lingüística sul-mato-grossense.

Já há algum tempo, ficou constatada a diversidade lingüística no Brasil, por meio de estudos realizados, principalmente, por José Jorge Paranhos da Silva (1879), Macedo Soares (1884), Amadeu Amaral (1922), Antenor Nascentes (1922), Mário Marroquim (1934), Serafim da Silva Neto (1950) e Nelson Rossi (1963), apenas para ficar nas principais investigações feitas no Brasil.

As variações lingüísticas identificadas nessas pesquisas, realizadas no português do Brasil, fazem que apareça um estudo preocupado com as diversidades da língua, visando à sua sistematização. Publica-se, então, em 1963, o Atlas Prévio dos Falares Baianos por Nelson Rossi.

Podemos dizer, com segurança, que a publicação de Rossi consiste no marco dos estudos dialetológicos no Brasil. Posteriormente, alguns estados passaram a publicar suas realidades lingüísticas nos seus Atlas, chamados regionais.

Em vista disso, os estudos dialetológicos tomam corpo no país e passam a ter responsabilidade por grande percentual de trabalho de campo em alguns estados do Brasil. A dialetologia começa a andar pari passu com as outras áreas do conhecimento, apesar de relegada a segundo plano até o final da década de 80 .

A dialetologia ressurge com grande força a partir do final da década de 90, com a elaboração da Carta de Salvador em 1996, assinada por lingüistas de todo o país e do exterior. Ao se referir ao fato, diz Oliveira (1998, p. 237-239) que:

Indubitavelmente, não se discute a importância de se fazer o trabalho dialetológico, tendo em vista a característica continental do país, as variações nele presentes e a heterogeneidade cultural [...] A retomada dos estudos dialetológicos, caracterizada pelo estímulo em fazer Atlas regionais e o Atlas Lingüístico do Brasil, põe em voga a relevância dos trabalhos multidisciplinares... 
Nas pesquisas atuais, a dialetologia se aliou à sociolingüística, fazendo um entrecruzamento metodológico, criando novas alternativas para as investigações. Assim é que o informante não precisa, obrigatoriamente, ser analfabeto e nem residir na zona rural. É muito importante, por outro lado, que o informante tenha nascido no local ou que para ele tenha vindo com até 8 anos de idade e que tenha cursado somente até a quarta série do ensino fundamental, podendo residir na região urbana. São mais acessíveis os da periferia, por estarem sempre dispostos a colaborar com a pesquisa.

Imperioso é realçar que, apesar do casamento entre a dialetologia e a sociolingüística, enquanto o questionário desta continua sendo dinâmico; daquela não deixa de ser estático. Acrescentamos, ainda, que em vista da união, outros fatores além do espacial foram levados em conta, como o social, faixa etária e a escolaridade.

Dado o fim especial deste escrito, que pretende ser útil ao conhecimento de alunos de graduação, é importante dizer que por dialetologia entendemos o estudo espacial e social, rural e urbano, da modalidade falada da expressão lingüística de uma região ou de um país.

\section{O Projeto Atlas Lingüístico de Mato Grosso do Sul}

O projeto tem origem com a primeira versão elaborada pela Professora Albana Xavier Nogueira (UNIDERP), que contou com o apoio e colaboração da Professora Maria José Toledo Gomes (UEMS).

Com a aposentadoria da Professora Albana e por decisão das duas colegas, assumimos a coordenação geral do Projeto desde 1996. A partir dessa data, responsabilizamo-nos pelo seu desenvolvimento no que respeita a relatórios, às primeiras reuniões em Campo Grande com colegas dos principais câmpi da Universidade Federal de Mato Grosso do Sul e às pesquisas de campo. A sede do Projeto fica no Câmpus de Três Lagoas da Universidade Federal de Mato Grosso do Sul, no câmpus I, onde fica, com boa infra-estrutura, a já conhecida sala do Attas, sob nossa coordenação.

Uma iniciativa que tivemos com sucesso, foi a elaboração da segunda versão do Projeto e o seu encaminhamento para a FUNDECT (Fundação de Apoio ao Desenvolvimento do Ensino, 
ciência e Tecnologia do Estado de Mato Grosso do Sul). A sua aprovação resultou em recursos para compra de gravadores e para as investigações feitas nos primeiros municípios das 32 localidades da rede de pontos do Estado.

Os deslocamentos iniciais foram feitos com apoio da FUNDECT, com recursos para alimentação e estada, e da PROPP/ UFMS, com a Base de Pesquisas do Pantanal, veículo com motorista para locomoção e auxílio para a compra de material de consumo.

Outra providência que tomamos para o desenvolvimento do Projeto foi a elaboração da VERSÃO III do Projeto ALMS, encaminhada ao CNPq (Conselho Nacional de Desenvolvimento Científico e Tecnológico), em 2003, em parceria com a UFRJ (Universidade Federal do Rio de Janeiro), Departamento de Lingüística e Filologia, representado pelos professores Maria Luíza Braga, Maria Cecília Mollica e Antony Julius Naro.

A procedência da escolha se deve ao pioneirismo da UFRJ em pesquisa da diversidade lingüística e ao seu prestígio comprovado no país que permitirá o aprimoramento de nossas orientações, sugestões, escolha de temas, e mesmo, um melhor tratamento científico dos dados. Os contatos com os pesquisadores parceiros foram feitos por meio de encontros específicos, seminários sobre as atividades do Projeto, discussões a respeito das interpretações dos dados e avaliações das cartas lingüísticas elaboradas.

\subsection{Justificativa}

Há pelo menos três razões muito fortes para a descrição da realidade sul-mato-grossense: a) as migrações: a aventura, a baixa densidade populacional, a terra fácil fizeram que para cá viessem mineiros, paulistas, goianos, principalmente, voltados para a pecuária e com isso abrindo fazendas e criando gado. Numa segunda circunstância, os paranaenses e gaúchos para o cultivo da terra. Necessário é acrescentar, ainda, pernambucanos, baianos e alagoanos, em sua maioria, na luta pela sobrevivência, dispostos a desenvolver quaisquer atividades; b) os nativos: a população indígena, segunda do país, com mais de 50.000 pessoas. De acordo com Cabral (2002, p. 33): 
[...] trata-se de grupos com histórias seculares de contado com a sociedade envolvente, o que, de certa maneira, explica a inserção destes povos, com um razoável grau de permeabilidade na sociedade brasileira, com diversas estratégias de resistência cultural, em suma, com formas bem definidas de enfrentamento, resolução ou fuga de conflitos, pelas quais conseguem equilibrarse no fio da navalha representado pelas alternativas de contato propostas pelas elites.

Ressaltamos que a diversidade cultural tem forte influência na expressão lingüística do Estado, constituindo-se numa de suas variações; e c) as regiões fronteiriças: marcadas pelo espaço e pelos seus habitantes com sérias interferências na linguagem das regiões. São freqüentes as ações comerciais e culturais dos paraguaios e bolivianos, além das relações empregatícias nas fazendas dos Pantanais.

Desnecessário é afirmar que essas três causas da variação da linguagem em Mato Grosso do Sul aparecem sob a forma de empréstimos (adoção do item lexical com alteração na sua estrutura), interferências (expressão da língua A, usada na língua B) e xenismos (palavra importada sem alteração). José Filho (2001, p. 11-12) constata a presença desses mecanismos em comunidade indígena. Veja:

O objetivo geral da pesquisa diz respeito ao estudo das interferências lingüísticas, oriundas do guarani em textos escritos em português [...] bem como estudo dos empréstimos lingüísticos e xenismos em texto escrito em guarani, tomados ao português e ao castelhano pelos educandos.

\subsection{Objetivos}

Com a realização da pesquisa, temos o propósito de: i) conhecer as características da modalidade falada em Mato Grosso do Sul; ii) oferecer aos estudiosos da língua portuguesa e pesquisadores de áreas afins contribuições para o ensino/aprendizagem da língua portuguesa, respeitando as variações regionais; iii) sistematizar dados para descrições nas diversas áreas do conhecimento; e iv) elaborar o atlas lingüístico de Mato Grosso do Sul. 


\subsection{Procedimentos metodológicos}

A rede de pontos é constituída por 32 localidades, distribuídas por cinco setores, cujos municípios principais são Três Lagoas, Corumbá, Aquidauana, Campo Grande e Dourados. A escolha das localidades teve por base aspectos demográficos, históricos e sociais.

Em cada localidade, foram selecionados quatro informantes, estratificados em sexo (masculino e feminino), grau de instrução (rudimentar ou com escolaridade até $4^{\text {a }}$ série do ensino fundamental) e naturalidade (nascido no município ou nele residido desde os 8 anos de idade).

A coleta dos dados foi feita por meio de entrevistas, utilizando-se do método direto e indireto, mediante questionário único com 557 perguntas, subdividido em aspectos fonéticos e lexicais. O morfossintático será estudado a partir das narrativas feitas pelos informantes sobre fatos acontecidos nas suas vidas que lhes tenham marcado a existência.

Os inquéritos foram gravados "in loco", com duração de mais ou menos três horas, feitos por acadêmicos de iniciação científica e por alunos do Programa de Mestrado em Letras de Três Lagoas. Nas transcrições fonéticas e grafemáticas, é utilizado o programa computacional SPDGL (Sistema de Processamento de Dados Geolingüísticos). Registramos, igualmente, que o grafemático tem por base as normas do Projeto NURC-SP (Projeto da Norma Urbana Regional Culta), que até agora são as únicas existentes do Brasil, sempre copiadas com alterações (para pior) por pesquisadores, com vistas à justificação de autoria.

Foram feitas doze viagens para fazer as entrevistas com os quatro informantes de cada localidade. As gravações foram feitas com aparelhos Sony e Panasonic, totalizando trezentas e oitenta e quatro horas, 128 informantes, sessenta e quatro homens e sessenta e quatro mulheres.

As perguntas do questionário se voltaram para as temáticas dos setores, conforme relação que segue:

i) acidentes geográficos

ii) fenômenos atmosféricos

iii) tempo

iv) flora 

v) fauna
vi) corpo humano
vii) doenças mais comuns
viii) funções do corpo humano
ix) características físicas
x) ciclos da vida
xi) religião e crenças
xii) vestuários e objetos de uso pessoal
xiii) brinquedos e diversões
xiv) sistema de pesos e medidas
xv) superstições, simpatias e lendas

Alguns estados brasileiros já possuem o seu atlas lingüístico. Em virtude de os estudos serem cíclicos, a dialetologia está, atualmente, em lugar de destaque nas pesquisas sobre linguagem. Cardoso (1996, p. 110) afirma que:

O caráter extensivo da Dialetologia, no sentido de que tem predominantemente uma abrangência espacial, diatópica, à qual se podem e devem agregar incursões sistemáticas de natureza sociolingüístico-estráticas, etárias, diafásicas, garante a sua atualidade e assegura a importância da expansão dos estudos nesse campo, pelo menos até que se tenha descrito todo o território brasileiro.

\subsection{Cartas lingüísticas}

Apenas para exemplificar, apresentamos duas cartas fonéticas, duas lexicais e duas morfossintáticas, com a descrição devida, para clarear a metodologia utilizada. Como vê o leitor, estamos no começo da elaboração das cartas, acompanhando ao mesmo tempo as outras atividades do Projeto. As cartas dependem, igualmente, de um aprimoramento do aspecto morfossintático, que será feito pela autora do programa SPDGL, a professora Hilda Gomes Vieira, responsável pelo curso ministrado em Mato Grosso do Sul, no ano de 2002. Vejam os exemplos: 


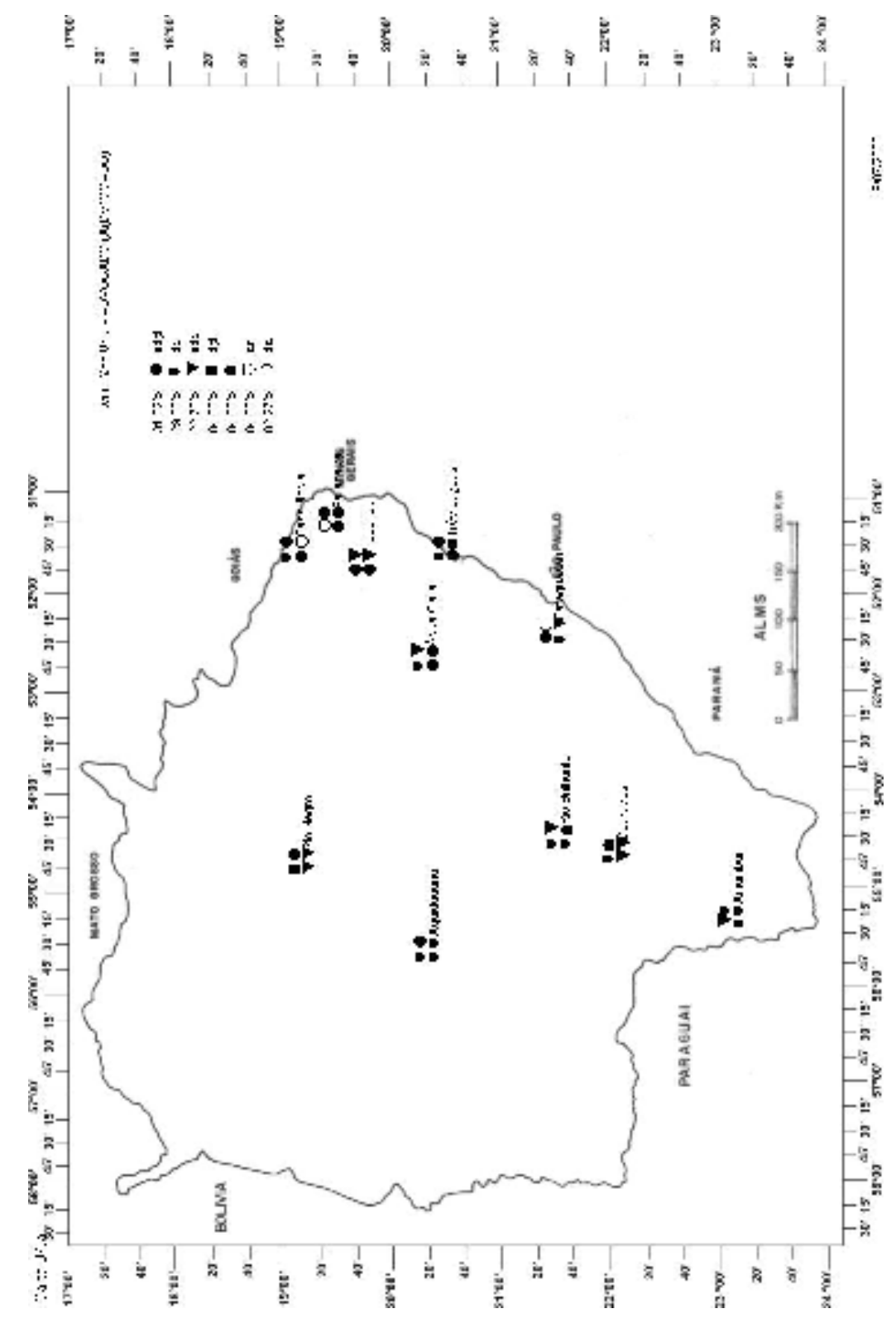




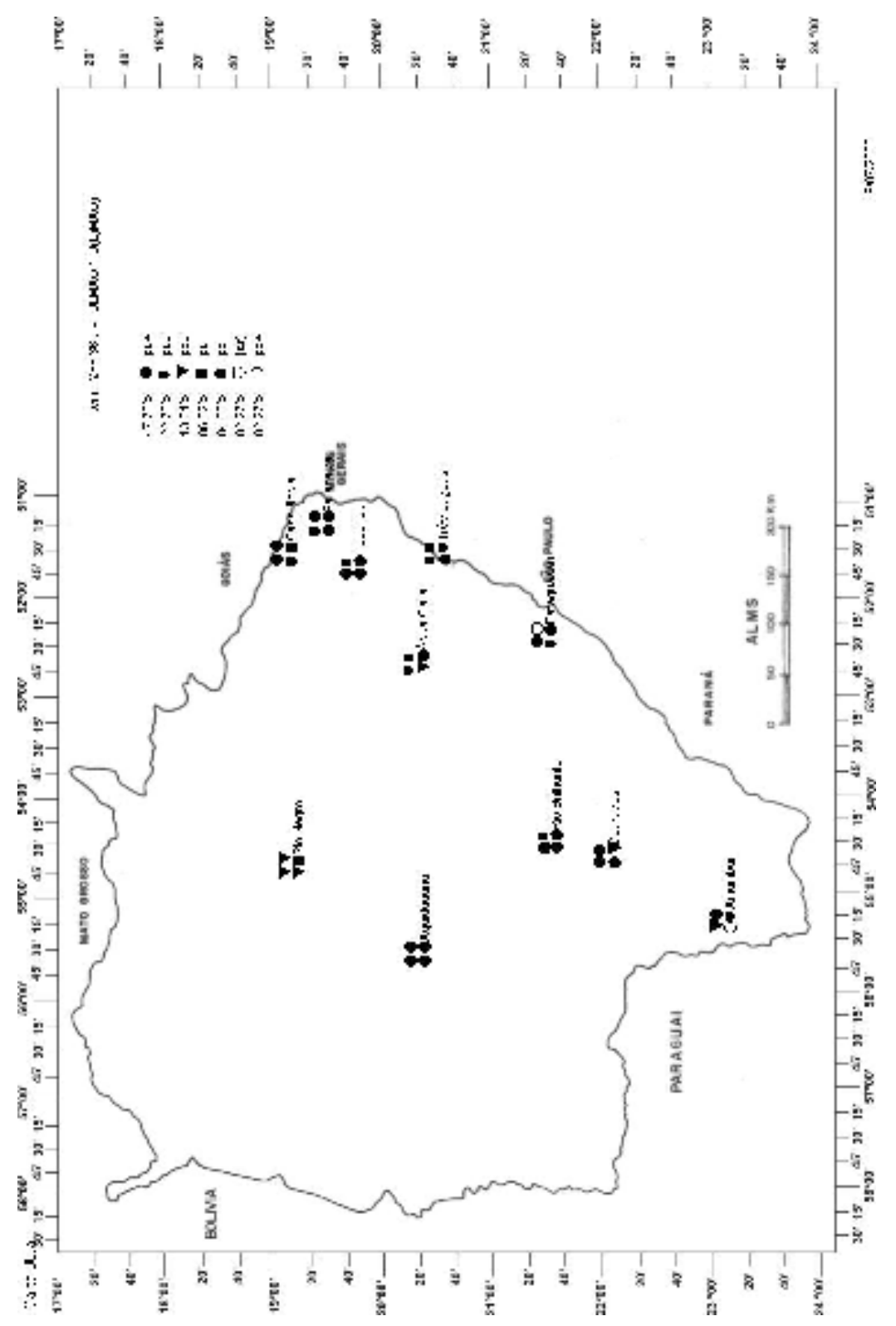




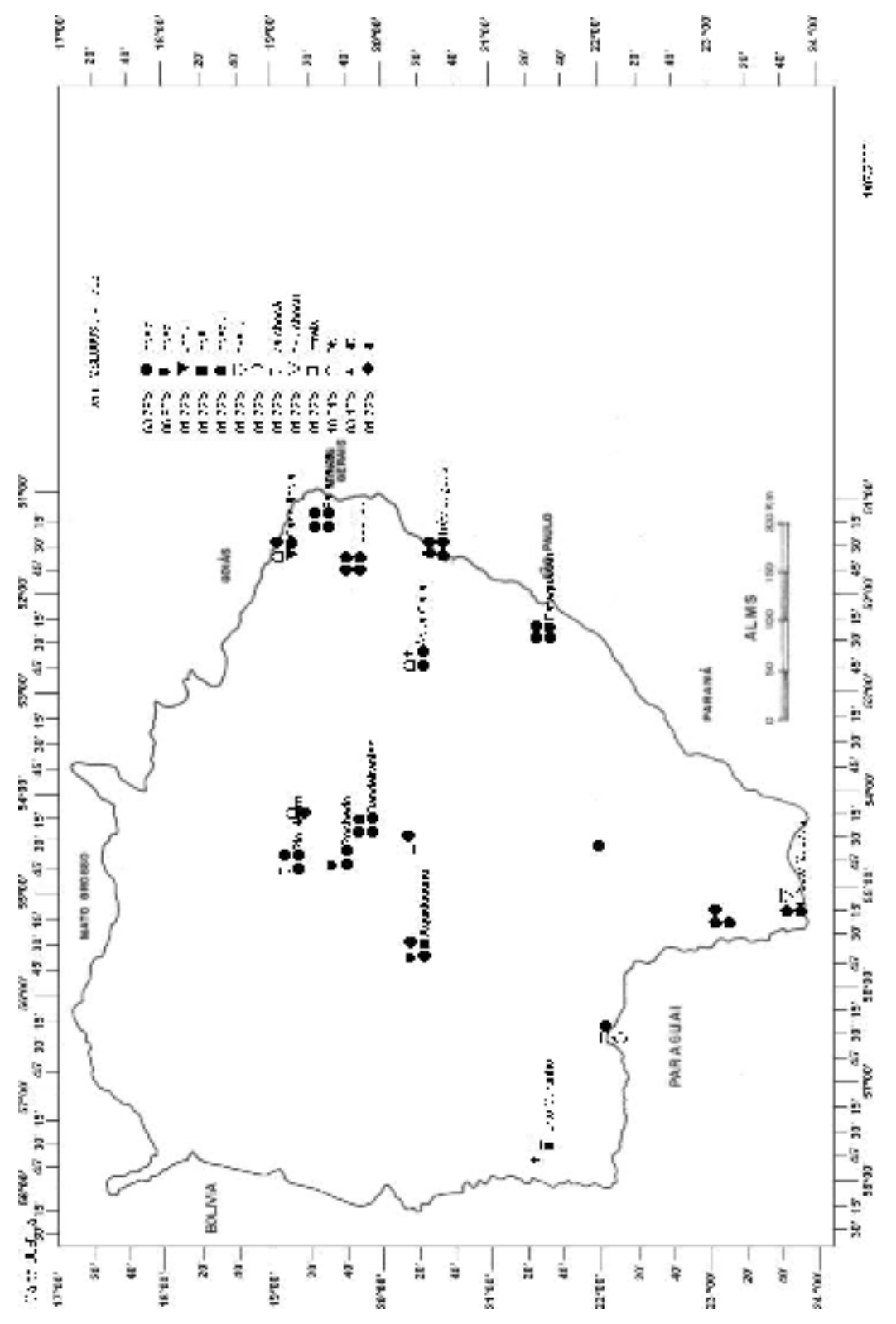




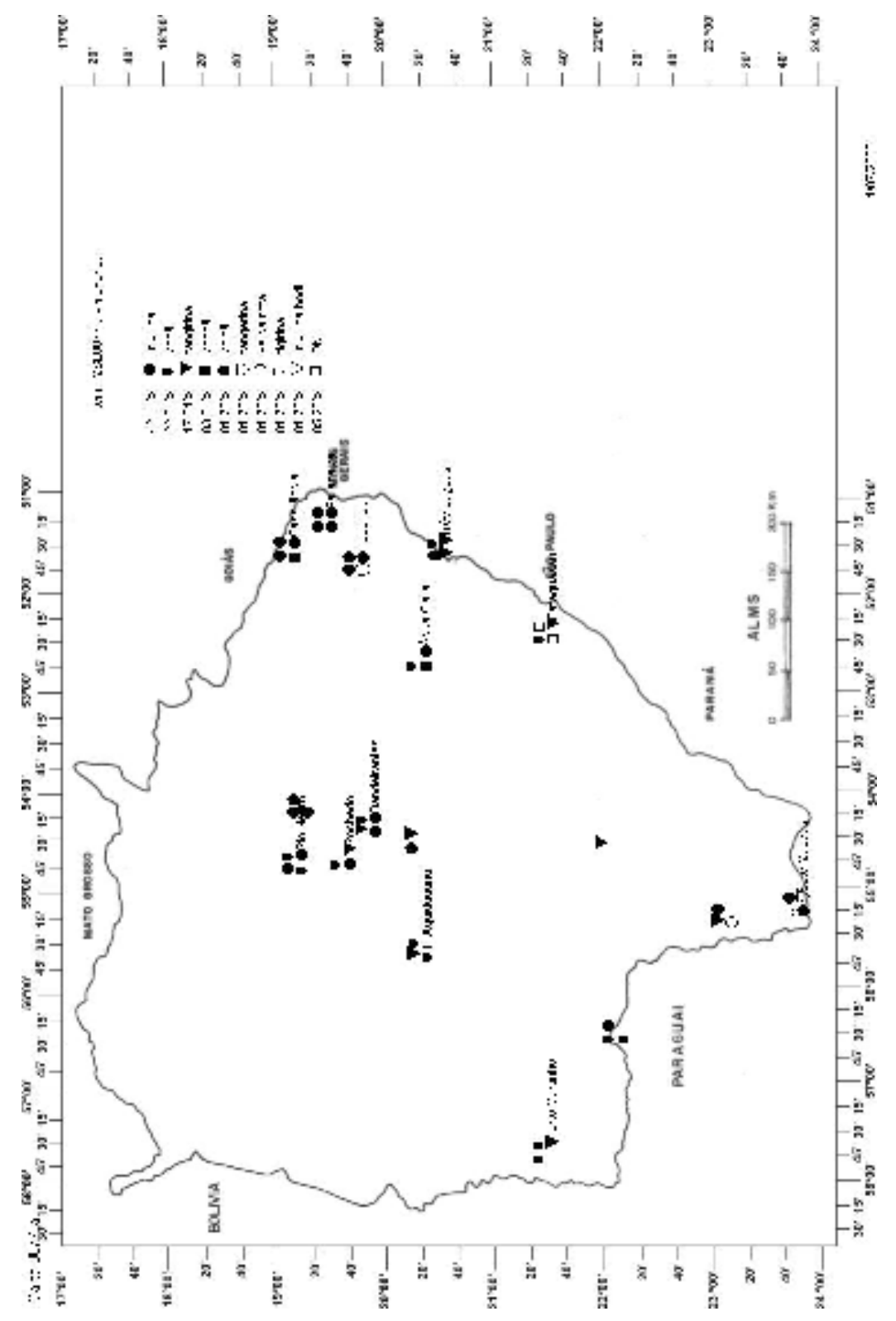




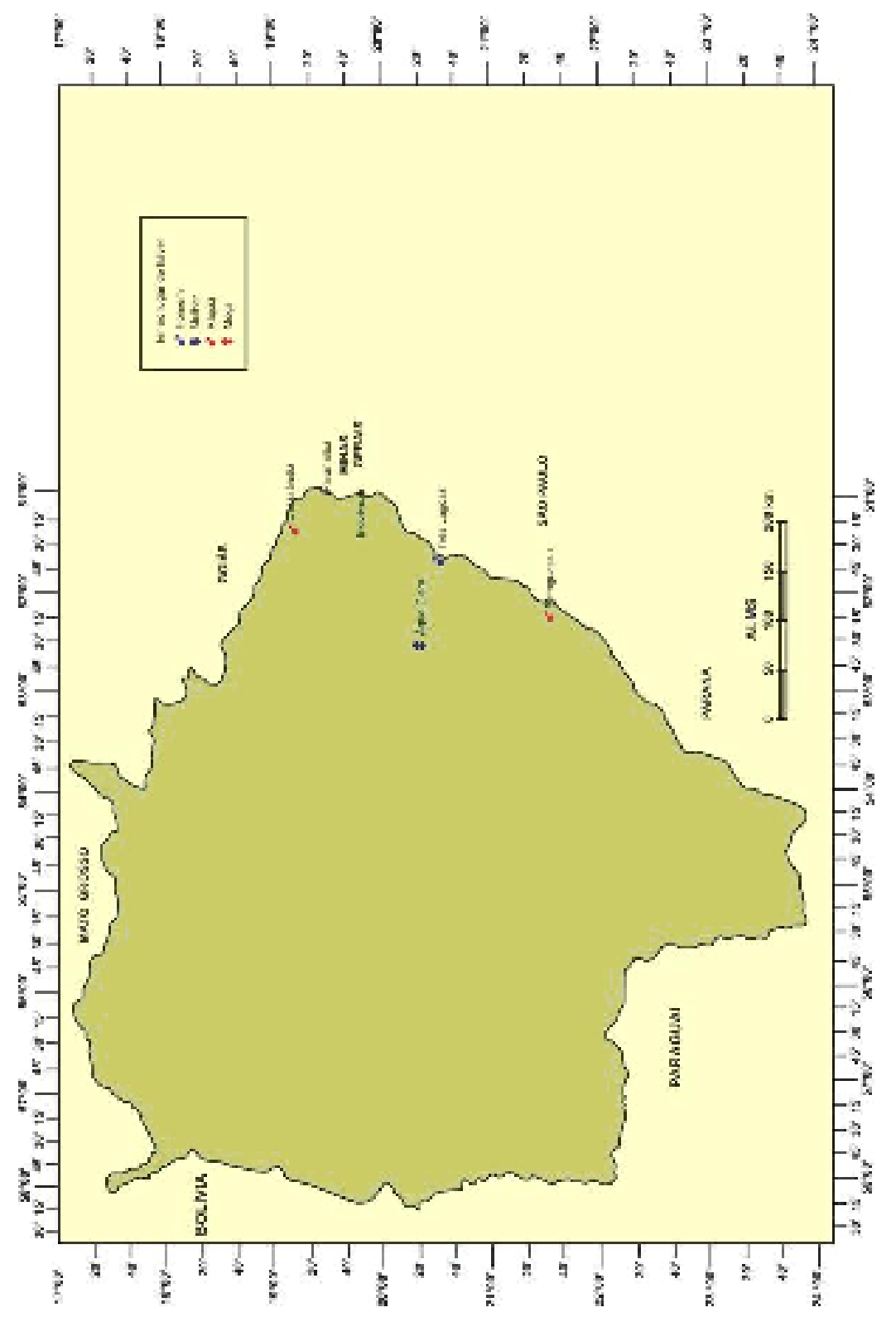




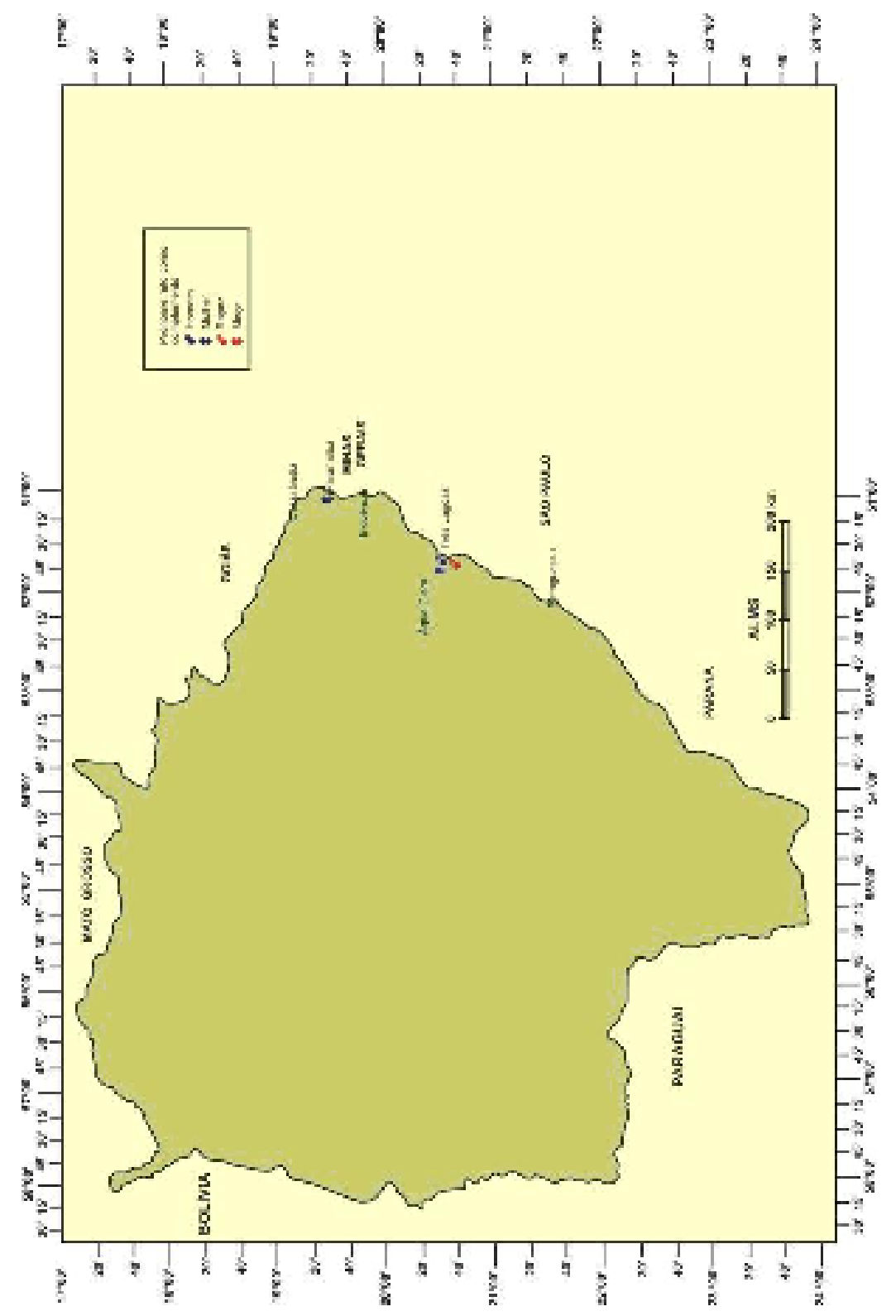


A carta fonética 07 trata das realizações do vocábulo advogado. O maior número de atualizações se deu com [adzi] presente em quase todas as localidades. A seguir, houve construções com [de] e depois com [ade]. Daí, [adzivo'gadu], [devo'gadu] e [adevo'gadu].

A carta fonética 36 se refere ao vocábulo pulmão. Na fala dos informantes, o maior índice foi com [puw], sendo a maneira de falar dos quatro entrevistados de Aquidauana. Em seguida, tivemos [pul], [pol], [pu] e [po]. Portanto, temos: [pul'mã̀], [pol'mã̀], [pu'mã̀], [po'mã̃] e [po'mã̀]. As convenções correspondem a DN (desconhece o nome) e NR (não respondeu).

No que respeita às cartas lexicais, a 93 corresponde ao item lexical indez, que teve na forma \{indeiz\} um número altíssimo de respostas, ausente apenas na localidade de Porto Murtinho. Esse dado leva em conta duas entrevistas. Ocorreram, ainda, as seqüências: \{indez\}, $\{$ xócu\}, \{indê\}, \{indezu $\},\{$ overu\}, \{pá chocá\}, \{ovu chocu $\}$ e \{intrêis\}. As convenções correspondem a DN (desconhece o nome), NR (não respondeu) e NL (não lembra).

A carta lexical 77 trata do item lexical mexerica. Como podem observar, são vários os sinônimos conforme seguem com a seguinte ordenação: $\{$ mixirica\}, \{pocã $\}$, \{tangirina\} e $\{$ mixirica bodi\}.

Como já foi dito, o questionário não tem, propriamente, o aspecto morfossintático, que é tirado das narrativas feitas pelos informantes, ao final da entrevista, em decorrência da dinamicidade da resposta. Provisoriamente, as cartas morfossintáticas não têm número. Este procedimento depende da reformulação que, em breve, será feita no programa.

A carta ter no lugar de haver nos mostra que a informante moça, em nenhuma localidade trocou o haver por ter, o rapaz fez a permuta de um pelo outro em Cassilândia e Bataguassu. O homem pôs ter no lugar de haver em Três Lagoas, e, a mulher, em Água Clara.

A carta Pronome reto como complemento denota que, somente em Paranaíba e Três Lagoas, os informantes colocaram o pronome reto como complemento do verbo. Em Três Lagoas, só a moça não fez a colocação, enquanto em Paranaíba, apenas a mulher empregou a modalidade sintática em questão. 


\section{Conclusão}

Neste texto, procuramos apresentar, bem de perto, um quadro das influências culturais sofridas pelo Estado de Mato Grosso do Sul que, conseqüentemente, iria refletir na sua realidade lingüística e mostrar os passos estabelecidos no Projeto Atlas Lingüístico de Mato Grosso do Sul.

Como é uma pesquisa que envolve trinta e dois municípios do Estado, com quatro informantes em cada um e um questionário muito longo demanda tempo, sacrifício e paciência. Na verdade, tolerância, porque os mais ligados a gabinetes têm dificuldade para entender a demora com que a reta final é atingida.

Finalmente, reafirmamos a importância da elaboração do Atlas Lingüístico de Mato Grosso do Sul, como um documento dos estudos da linguagem, que muito contribuirá para o ensino do português em terras sul-mato-grossenses e o nosso reconhecimento pelo apoio do CNPq (Conselho Nacional de Desenvolvimento Científico e Tecnológico) e da PROPP (Pró - Reitoria de Pesquisa e Pós Graduação) da UFMS.

\section{Referências Bibliográficas}

CABRAL, Paulo Eduardo. Educação escolar indígena em Mato Grosso do Sul: algumas reflexões. Campo Grande: SEEMS, 2002.

CARDOSO, Suzana Alice Marcelino. A dialetologia no Brasil: perspectivas. DELTA, São Paulo, EDUC, v. 15, p. 233-255, fev./ago. 1999. Edição especial.

JOSÉ FILHO, Antonio. A língua dos Kaiowa/Guarani: interferências, empréstimos lingüísticos e xenismos. 2001. Dissertação (Mestrado em Letras: Lingüística) - Universidade Federal de Mato Grosso do Sul, Três Lagoas, 2001.

OLIVEIRA, Dercir Pedro de. O estudo dialetológico no Brasil: a volta ou a sedimentação de uma metodologia de trabalho. In: AGUILERA, Vanderci de Andrade. A Geolingüística no Brasil: caminhos e perspectivas. Londrina: Ed. UEL, 1998. p. 235-241. 